\title{
A Review of Energy Management Assessment Models for Industrial Energy Efficiency
}

\author{
A S M Monjurul Hasan (1) and Andrea Trianni *(i)
}

School of Information, Systems, and Modelling, Faculty of Engineering and IT, University of Technology Sydney, 81 Broadway, Ultimo 2007, Australia; asmmonjurul.hasan@uts.edu.au

* Correspondence: andrea.trianni@uts.edu.au

Received: 25 September 2020; Accepted: 29 October 2020; Published: 1 November 2020

check for updates

\begin{abstract}
The necessity to ensure energy efficiency in the industries is of significant importance to attain reduction of energy consumption and greenhouse gases emissions. Energy management is one of the effective features that ensure energy efficiency in the industries. Energy management models are the infancy in the industrial energy domain with practical guidelines towards implementation in the organizations. Despite the increased interest in energy efficiency, a gap exists concerning energy management literature and present application practices. This paper aims to methodologically review the energy management assessment models that facilitate the assessment of industrial energy management. In this context, the minimum requirements model, maturity model, energy management matrix model, and energy efficiency measures characterization framework are discussed with implications. The study concludes with interesting propositions for academia and industrial think tanks delineating few further research opportunities.
\end{abstract}

Keywords: energy management; industrial energy efficiency; energy management practices; assessment model

\section{Introduction}

The industrial sector, being one of the largest entities for consuming energy [1], is responsible for $30 \%$ of total carbon emission [2]. Further, the up-rising of energy expenses, stringent environmental restrictions, and fossil fuel depletion have shaped increased demand to the reduction of energy consumption and its associated costs in the industries [3]. In this context, ensuring energy efficiency is one of the significant mainstays of the industrial processes that must be addressed as a priority. Energy efficiency gains through the implementation of energy management practices can provide multiple benefits to an organization ensuring the optimum usage of energy resources maintaining the desired energy productivity level and reduce the energy costs [4-6].

The energy management programs are being developed to endorse energy efficiency in the industries for facilitating energy savings, reduction of greenhouse gas emissions, and productivity benefits $[7,8]$. However, industrial energy efficiency still remains unattained $[9,10]$; with low implementation rates of energy efficiency measures [11,12] because of certain barriers [13,14], although research has shown its immense potential. There are multiple studies conducted at local, regional, national, and multinational focusing the barriers to adopt energy efficiency in the industries [15-19]. On the contrary, the drivers are also found towards energy-efficient technology adoption by several studies [20-22]. The energy efficiency gap has been conferred, keeping the relevance on technical aspects and appliances [23], whilst it has also incorporated behavioral issues [24].

Energy management and energy services are mostly studied through theoretically or conceptually, whilst energy management practices are studied in an empiric way [25]. Academic studies have been conducted regionally and beyond by many researchers about energy management practices and their 
characterization [15,26-28]. Energy management practices, as well as energy services, are perceived as significant explanations, and few efforts are paid to depict them including the assessment model to facilitate industrial think tank focusing particular set of actions for improved energy management [24]. It is notable to mention that research mainly acquainted the idea of an "extended energy efficiency gap", expressing the gap abide by technical as well as managerial components. In addition, a vast portion of unexplored market potential namely "energy service gap" exists because of high operating cost at the industrial application phase [29], even though energy services speak for a favorable market-centric resolution for improved energy efficiency [30]. So far, the avenues between integration of energy management with production systems are unexplored. Further, energy management into industrial decision-making process is not discussed thoroughly till now. Therefore, it is imperative to explore the domain of energy management to support industrial decision-makers pointing to the specified actions which are required to minimize the energy management lagging aspects, still keeping mind the multi-dimensional context and complexity of industrial energy management systems [31,32].

Given the introductory context, the paper aims to methodologically review the energy management assessment models that facilitate the assessment of industrial energy management. Notably, this study does not consider energy generation part and confines its focus to energy management framework only to help the industrial decision-making process covering energy consumption aspects in the industries.

This study is novel considering the fact that there has not been any study focusing on energy management 4.0 in the industrial decision-making process and comprehends the energy management framework to the best of authors' knowledge. In this study, we have worked to synthesize this gap in the greater interest of academia. By doing the review, we want to highlight future research avenues having nexus with energy management and industrial energy efficiency. Interestingly, all of the present research gaps fall into the big area, which is energy management 4.0 in industrial decision making. On another note, this study would help the industrial managers and engineers by figuring out improvement options in their energy management activities and supply chain system. In addition, the available options for policymakers to address energy management regulations are also incorporated in this study.

The rest of this paper is designed as follows: an introduction to the energy management concept is presented in Section 1. Section 2 describes the methodology. Section 3 provides the descriptive results of reviewing the literature on energy management assessment model. Subsequently, this paper concludes with explaining and incorporating the results in Section 4. Section 5 presents the concluding remarks.

\section{Methodology}

A systematic and rigorous review process was conducted in this paper. The primary focus of such reviews is to point out the related available studies established on pre-formulated research queries to synthesize the conclusion based on the evidence [33]. It is notable to mention that the systematic review features substantial leverages contrast to conventional narrative approaches of literature work. The conventional review does not apprehend formal methodological approaches, whilst the systematic review incites to minimize research biases through the adoption of search strategies, preordained inquiry string, and inclusion and elimination criterion [33]. Moreover, the comprehensive documentation nature of review enhances the clarity of review as well as facilitates subsequent replication [34].

In this paper, the relevant literature search methodology comprised of scientific literature sources, mainly the "Scopus" and "Web of Science" as both of the sources are well accepted in academia for their research quality and reliability [35]. We checked the online databases indexed in "Scopus" and "Web of Science" to identify the articles based on our keyword. In this research, the selected keywords to sort out the literature are "Energy Management", "Industry", "Energy Management Model", "Energy Management Practices", and "Energy Efficiency". Nonetheless, there was no specific starting timeframe for searching the literature in the database, though attempts were made to consider the recent researches. Table 1 presents the selection basis of the literature review. 
Table 1. Selection basis of the literature review.

\begin{tabular}{cl}
\hline Heading & \multicolumn{1}{c}{ Remark } \\
\hline Research domain & Energy; Engineering; Management \\
\hline Search string & $\begin{array}{l}\text { Industrial Energy Management; Energy management } \\
\text { Practice; Energy Management Framework }\end{array}$ \\
\hline Publication Type & $\begin{array}{l}\text { The academic journals, conference proceedings, and book } \\
\text { chapters. Working papers are not considered due to their } \\
\text { review process state and reliability issue [36]. The included } \\
\text { publications are Elsevier, Springer, IEEE Xplore, MDPI, } \\
\text { Taylor \& Francis, John Wiley \& Sons, and Emerald. }\end{array}$ \\
\hline Availability & Available online \\
\hline Area & Industry \\
\hline Relevance & $\begin{array}{l}\text { Articles articulate energy management; energy efficiency } \\
\text { proceedings at the institutional perspective }\end{array}$ \\
\hline Time & Focus on the recent researches \\
\hline
\end{tabular}

Each of the selected articles has been checked manually for content analysis in stage 2, the "screening" process. During the screening process, expulsion criteria that are followed in this research are presented in Table 2. Articles were discarded in this stage based on the criterion EXC 1, EXC 2. In stage 3, a backward review was conducted to reconsider relevant articles based on our selected keywords. The following stage consists of the exclusion of articles based on the criterion EXC 2, EXC 3, EXC 4, EXC 5, EXC 6, and EXC 7. Finally, the last step of methodology replicates the content analysis of selected articles. The entire methodological steps are illustrated in Figure 1.

In the phase of analyzing the content, it was essential to distinguish between energy management and energy management assessment framework/model. Therefore, the situation was very critical and decisive to the inclusion of such specification in this study. Nonetheless, discarding any concept related to energy management and its framework additional resolutions and aspects were also introduced that were not considered in the initial phase.

Table 2. Exclusion criterion of the literature.

\begin{tabular}{cl}
\hline Exclusion Heading & \multicolumn{1}{c}{ Remark } \\
\hline EXC 1 & The article published not in English \\
EXC 2 & $\begin{array}{l}\text { The article uses "Energy management" term only in title } \\
\text { and does not incorporate in any energy management } \\
\text { framework or model in an elaborated form }\end{array}$ \\
\hline EXC 3 & $\begin{array}{l}\text { The article uses “Energy management" only as a part of the } \\
\text { future research direction or future perspective }\end{array}$ \\
\hline EXC 4 & The article uses "Energy Management" just as a cited term \\
\hline EXC 5 & $\begin{array}{l}\text { Articles deals only with drivers, barriers to energy } \\
\text { management practices in the industries }\end{array}$ \\
\hline EXC 6 & Availability of full texts \\
\hline EXC 7 & Working papers \\
\hline
\end{tabular}




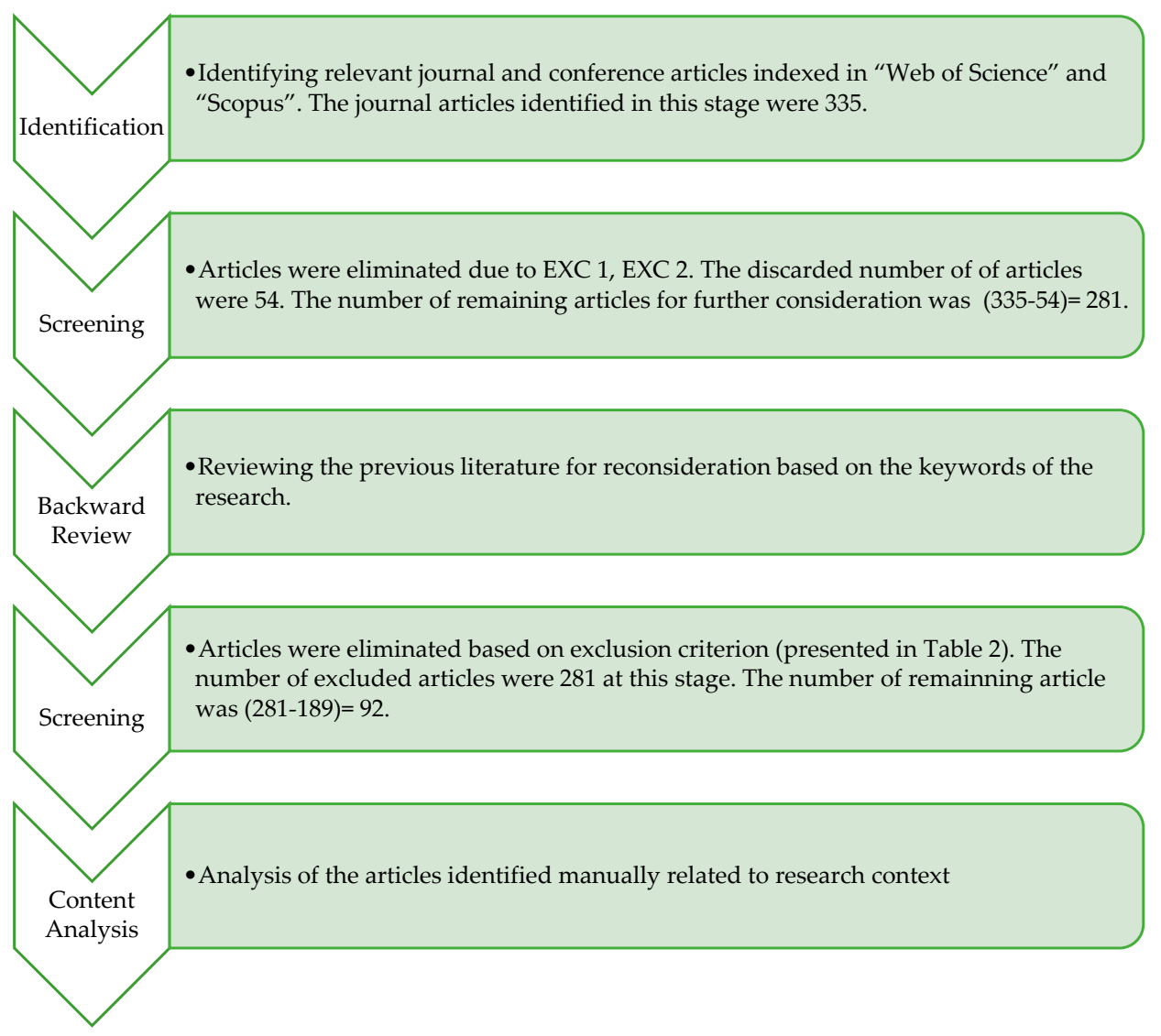

Figure 1. The methodological steps followed in the research.

\section{Results and Analysis}

\subsection{Energy Management Definition}

Defining energy management is significant when it comes to the point at energy management modelling or energy system practices implementation. Energy management concept is specified by many studies that incorporate multiple arenas. The prime areas covered by multiple studies to define energy management are energy consumption, strategic aspect, the involvement of managerial perspective, and people relevancy [25].

The German Federal Environment Agency defined energy management as the inclusion of planned and execution of actions to ensure predefined performance by a minimum amount of energy input [37]. B.L. Capehart has characterized the term energy management as the proficient and effective usage of energy towards maximization of profits and increasing reasonable positions [38]. $\mathrm{O}^{\prime}$ Callaghan et al., defined the energy management as the application of resources in regards of supply, conversion, and utilization which integrates monitoring, measurement, archiving, critical examination and analyzation, control, and rerouting of energy as well as material flows through the systems for ensuring minimal energy usage and achieve meaningful goals [39]. To define energy management, Bunse et al. focused on the inclusion of control, supervision, and improvement activities towards energy efficiency [6]. On the contrary, Ates et al. strengthened on the combination of techniques, activities, and managerial processes that leads to reduce energy cost and anthropogenic emissions [40]. One of the studies by Abdelaziz et al. promoted energy management focusing on energy optimization strategy that incorporates compelling the energy demand [41]. A comprehensive definition of energy management has been proposed by Schulze et al. that incorporates all necessary energy management elements and energy management practices in the industries [32]. 
In academic literature, energy management is portrayed as a holistic combination of applying resources, conversion, and application of energy $[16,20,25,32]$. The system involves checking, auditing, recording, scrutinizing, and more importantly controlling the energy flows to ensure the minimum consumptions of energy but to achieve maximum energy productivity [16,42]. Academicians have pointed some of the minimal prerequisites for implementation and operation of energy management in the industries $[27,40,41,43,44]$. Table 3 illustrates the requirements toward energy management with specifications whether the requirements are considered full, partly, or not under consideration.

Table 3. Minimal prerequisites for energy management in the industries. This table is adopted from Schulze et al. [32].

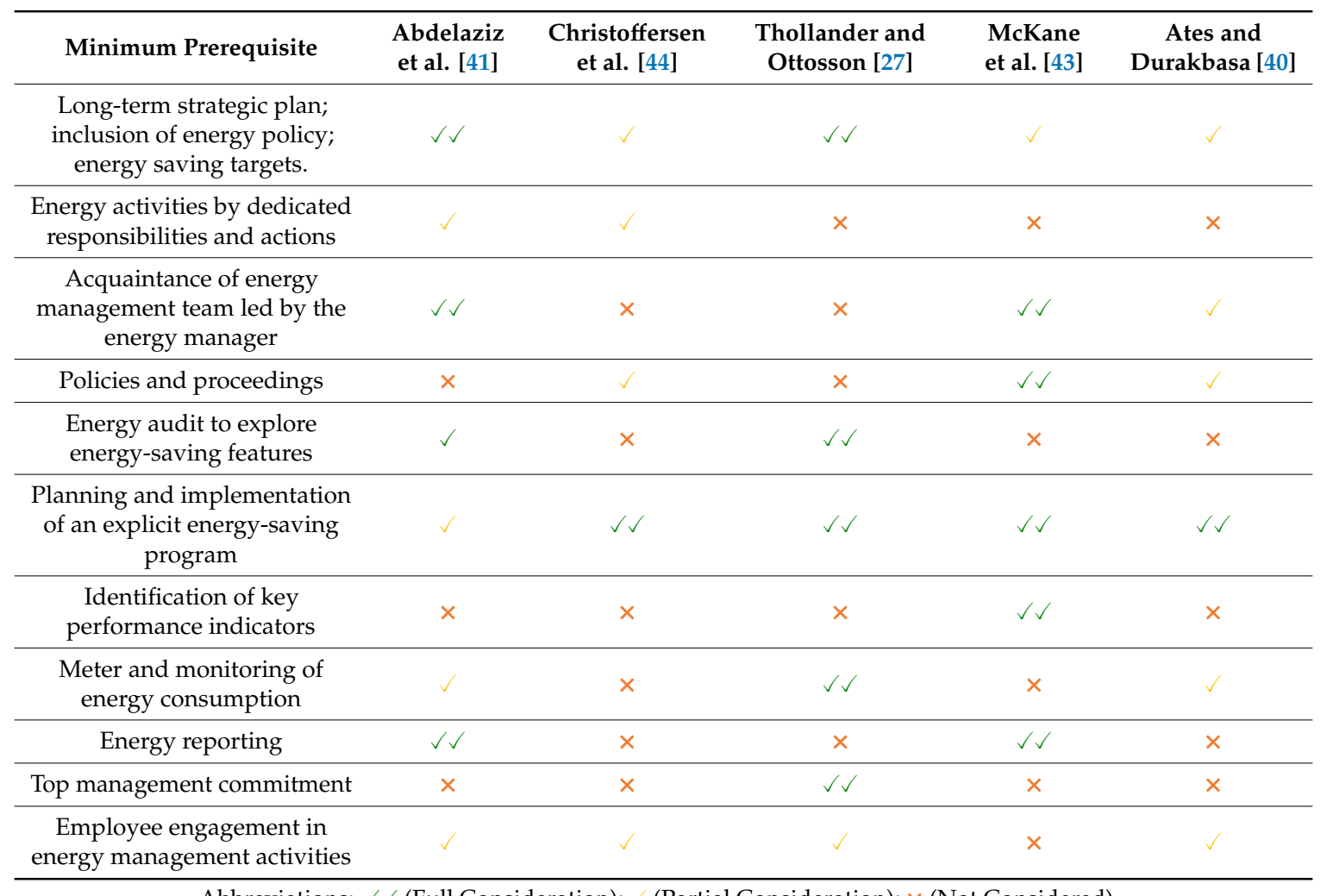

Abbreviations: $\checkmark \checkmark$ (Full Consideration); $\checkmark$ (Partial Consideration); $\times$ (Not Considered).

It becomes discernible by analyzing the minimum requirements for energy management from Table 3 that the sets of minimum requirements elucidated in the studies contrast in the number of elements as well as conformation of the individual features. In addition, it shows indistinctness on the conclusiveness of the list of minimum requirements whether it is suitable to describe a fully developed energy management. By analyzing earlier contributions on the topic, we can note the lack of a comprehensive conceptual framework about energy management. Therefore, in this study, we respond to this research gap by complying a review of academic journal publications in the area of industrial energy management and use its results to propose future research avenues to explore further. 


\subsection{Approaches to Energy Management Models}

There are research streams which are considered in academia as well as the industries to assess the energy management models. The streams can be categorized as "Minimum requirements", "Maturity models", and "Energy management matrixes" [25]. Furthermore, there is assessment tool namely "Energy Management Measures Characterization Framework", so to shape the energy management aspects accordingly". This is practice based, therefore basing on energy management practices with characteristics.

\subsubsection{Minimum Requirements}

The ISO 50001 standard that deals with energy management issues is incorporated at the first stream and thus apprehends guidelines to enable energy management system [45]. Enabling the organizations towards energy efficiency is the primary purpose of ISO 50001 Energy Management System standard. The standard is reviewed and published by the ISO/TC 301 Technical Standardization Committee, Energy Management, and Energy Saving in 2018 [45]. The protocol has a high level of hierarchical structure consists of ten chapters with a homologous architecture. The ISO 50001 standard is a consistent improvement framework which consists of "Plan-Do-Check-Act" at organizational practices. Table 4 presents the phases that are comprehended at ISO 50001 Energy Management System standard. However, it does not apprehend the critical assessment of the enterprises' effectiveness for a taken initiative of particular energy management practice. In addition, the initial stream incorporates primary endeavor to evaluate energy management, maintaining the limit of analysis $[40,44]$.

Table 4. The continual phases of ISO 50001 Energy Management System standard [45].

\begin{tabular}{cl}
\hline Phase & \multicolumn{1}{c}{ Remark } \\
\hline & $\begin{array}{l}\text { To apprehend the organizational context; incorporation of } \\
\text { energy policy; incorporation of energy management team; } \\
\text { consideration of actions towards risks and opportunities; } \\
\text { conduct of energy review; identification of significant } \\
\text { energy uses and establishment of energy performance } \\
\text { indicators; energy baseline; objectives and energy targets; } \\
\text { necessary action plans to improve energy performance in } \\
\text { accordance with the organization's energy policy. }\end{array}$ \\
\hline \multirow{2}{*}{ Do } & $\begin{array}{l}\text { Implementation of the action plans; operation and } \\
\text { maintenance controls, and communication; ensuring } \\
\text { competence in energy domain i.e., energy performance in } \\
\text { design and procurement. }\end{array}$ \\
\hline Check & $\begin{array}{l}\text { Monitor; quantify; analyzation; evaluation; audit and } \\
\text { conducting management review of energy performance } \\
\text { as well as energy management system. }\end{array}$ \\
\hline \multirow{2}{*}{ Act } & $\begin{array}{l}\text { Activities to address non-conformities and continuation } \\
\text { for improving energy performance. }\end{array}$ \\
\hline
\end{tabular}

\subsubsection{Maturity Models}

This second stream solicits a systematic perspective for assessing energy management in the organization [8] that includes the analysis for the requisite steps to enact energy management system [46]. Continuous improvement options are one of the significant features of maturity model. Therefore, the maturity model is accepted and popular in academia as well as industries since the development of the capability maturity model (CMM) [47-49]. The maturity models help the institutional enterprises surmount the austerity and enhance the quality by measuring institutional maturity based on particular or multiple domains with the help of predefined rules [50,51]. However, the maturity models are single dimensioned that focus either on objects maturity or process maturity, whilst the process maturity levels are dominant than the object-based model [52]. In one of the studies, Bojana et al. presented the 
maturity stages of energy management at activity levels [53]. Figure 2 exhibits the levels considered in maturity models for energy and utility management.

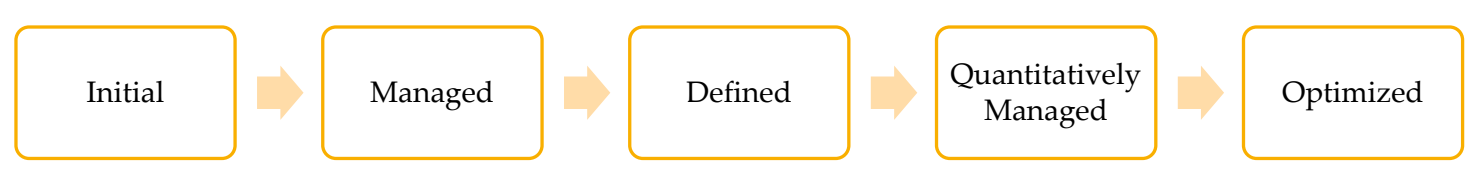

Figure 2. The levels in maturity models for energy and utility management (Source: [54]).

\subsubsection{Energy Management Matrixes}

The energy management matrixes are incorporated with the third stream $[55,56]$, which confers multiple similarities with the maturity model. It offers an insight into the present approach to energy issues in a company and helps the management to improve energy efficiency by integrating feedback. It also shows the substantial improvement potential in energy efficiency that is achievable by technical activity alone. However, the application of the energy management matrix in a wider range of industrial organizations has acknowledged manifold activities towards improvement of energy management practice. In addition, it puts the hitherto isolated technologically-based attempts to improve energy efficiency in a more effective management framework, often for the first time. The high standpoint from an analytical perspective, maturity concept conversion into a sophistication level along with a self-appraisal approach based on organization's perspective are the common points of energy matrixes with maturity models. Hence, no additional benefits are provided from these models in terms of approaches and aspects considered for reasoning. However, introducing assessment models have brought an amelioration that incorporates detailed activity list considered as energy management practices, whilst critical factors have not been addressed for evaluation [56,57].

\subsubsection{Energy Efficiency Measures (EEM) Characterization Framework}

The EEM characteristics are delved by the fourth research stream [58]. The energy efficiency measures characterization framework is important to formulize in the context of information sharing both for the policy and decision-makers about energy efficiency measures. Thanks to improved knowledge and information on industrial energy efficiency measures. Indeed, the policymakers could have enhanced support to develop the operative policies for endorsing energy efficiency at the industries. In addition, the improved knowledge on energy efficiency measures characteristics can articulate in-depth comprehension of the bottlenecks that hindering the implementation of energy efficiency processes [59]. Indeed, this is an interesting fact for resolution and policy makers.

Fleiter et al. exhibited detailed and thorough narratives of characterizations that facilitated understandings of the endorsement process for EEMs [58]. The framework encompasses twelve diverse features of energy efficiency measures which are emanated from the field of technical, relative advantage, and informational perspective. Worrell et al. characterized and grouped the energy efficiency measures into multiple attributes such as waste, emission, operation and maintenance, productivity, working environment, among others, where the secondary benefits are listed [60]. On the contrary, Trianni et al. devised a framework to explore energy management practices [59]. An inclusive view on energy efficiency measures integrating the recent applicable perspectives is encompassed in this framework for industrial decision-makers. The framework has inferred in specifying energy alongside the environmental and financial aspects. Moreover, the impact on production system, including the application aspects and interaction with other systems of energy efficiency measures are also considered in the framework. Another noteworthy feature of the framework is the inclusion of corporate involvement, which is important for industrial decision-makers and policy delegates. Moreover, the inclusion of the attribute set related to non-energy benefits is one of the salient features that has been neglected in the earlier characterization framework. Nonetheless, analytical factors of energy management activities are not portrayed comprehensively. Lung et al. affirm about the impact of additional savings and productivity benefits stemming from energy efficiency initiatives 
resulting in more compellingly. The authors focused on the methodology to characterize the attributes of productivity benefits as well as ancillary savings into a payback forecasting framework [61].

Another model has been proposed in a contemporary study by Trianni et al. in the domain of characterization framework to assess industrial energy management, focusing on the benchmarking of energy management practices [25]. In this model, three elements have been considered that are energy management practice lists followed by specific baseline for benchmarking the performances and optimal threshold adoption in the assessment. The notable aspects of this model are the energy management practice adoption evaluation and more comprehensiveness output compared to the other models. More importantly, it features elaborate energy management approaches and capabilities assessment to an indistinct evaluation of energy management practices. On the contrary, Sorrell [62] and Benedetti et al. [63] have considered three-dimensional classification framework focusing to energy service contracts. The framework of Sorrell is customer perspective based and consisted of "Scope", "Depth", and "Finance" dimension. Benedetti et al. considered "Scope", "Intangibility of the Contract", and "Degree of Risk".

The synopsis of the existing management assessment models is presented in Table 5. 
Table 5. Synopsis of the existing energy management assessment models. The table is an aggrandized approach of Trianni et al. [25].

\begin{tabular}{|c|c|c|c|}
\hline Category & Model Narration & Remark & Reference \\
\hline $\begin{array}{l}\text { Minimum } \\
\text { requirements }\end{array}$ & $\begin{array}{l}\text { Significant features: energy policy, energy saving goals } \\
\text { (quantitative) or aspirations regarding energy-saving projects } \\
\text { and their implementation. Energy efficient purchases, specific } \\
\text { allotment of energy responsibility and tasks. Functioning } \\
\text { engagement of stakeholders, specially the employees by } \\
\text { apprising, persuading, and educating. }\end{array}$ & $\begin{array}{l}\text { This model consider the energy management as a } \\
\text { comprehensive management system. Focused on policy, } \\
\text { energy saving goals and specific energy saving projects. } \\
\text { However, the model does not integrate the energy manager } \\
\text { concept. Furthermore, there is no clear guideline about top } \\
\text { or mid-level management support to achieve energy } \\
\text { savings. Though, involvement of employee to energy } \\
\text { saving related work are suggested. }\end{array}$ & [44] \\
\hline
\end{tabular}


Table 5. Conts.

\begin{tabular}{|c|c|c|c|}
\hline Category & Model Narration & Remark & Reference \\
\hline \multirow{7}{*}{ Maturity Models } & $\begin{array}{l}\text { Five stages: preliminary, arrange, delineate, managed in } \\
\text { quantitative form and reformed; Novel process avenues are } \\
\text { regulated towards progress focusing on environmental aspect; } \\
\text { Four maturity phases: practice enactment, standardization of } \\
\text { practice, performance management and recurring phase for } \\
\text { improvement. }\end{array}$ & $\begin{array}{l}\text { The model used Capability Maturity Model Integration } \\
\text { (CMMI) as a reference framework and extended to } \\
\text { environmental management context. It comprised of } \\
\text { particular procedures for energy as well as resource } \\
\text { management. No clear guideline about dedicated energy } \\
\text { manager. }\end{array}$ & {$[54]$} \\
\hline & $\begin{array}{l}\text { Instructions to attain improved energy efficiency and amenability } \\
\text { with energy management standards especially ISO 50001. Energy } \\
\text { management actions are categorized into five maturity phases } \\
\text { subsequent to the PDCA cycle. }\end{array}$ & $\begin{array}{l}\text { The framework adapts manifold energy management } \\
\text { practices based on PDCA cycle. Notably, top management } \\
\text { support is incorporated in the framework. Energy } \\
\text { management roles are characterized. However, no clear } \\
\text { indication about energy manager inclusion in the process. }\end{array}$ & {$[64]$} \\
\hline & $\begin{array}{l}\text { Five levels: Emerging, Define, Integration, Optimization and } \\
\text { Novelty; four sections on the basis of PDCA cycle, } 16 \text { pillars, and } \\
63 \text { sub-pillars. The model allows } 5 \text { attribution promulgation for } \\
\text { each sub-pillar to evaluate the maturity. }\end{array}$ & $\begin{array}{l}\text { Energy management review along with action plan are } \\
\text { integrated to the framework. In addition, competence } \\
\text { building feature is also included. }\end{array}$ & [65] \\
\hline & $\begin{array}{l}\text { Primary features for the energy consumption management } \\
\text { keeping alignment to ISO 50001. Five phases: initial, intermittent, } \\
\text { planning, supervisory and optimal. } 5 \text { dimensions that are } \\
\text { portrayed as requisite for success: consciousness, information, } \\
\text { and expertise (utmost significant); methodological proposition; } \\
\text { energy performance management and archiving system; } \\
\text { institutional architecture; alignment with strategy. }\end{array}$ & $\begin{array}{l}\text { The tool is not incorporated with inclusion of energy } \\
\text { manager. }\end{array}$ & [8] \\
\hline & $\begin{array}{l}\text { Incorporation with ISO 50001; knowledge base creation for } \\
\text { self-assessment along with monitoring and improvement. } \\
\text { The levels are depicted for each ISO } 50001 \text { process instilled } \\
\text { by Eric et al. [54]. }\end{array}$ & $\begin{array}{l}\text { The assessment tool includes top management } \\
\text { commitment, and energy manager appointment with other } \\
\text { manifold energy management practices. }\end{array}$ & [53] \\
\hline & $\begin{array}{l}\text { Salient features are the assessment of compelling factors for } \\
\text { energy management adoption, contribution towards a better } \\
\text { understanding of suitable energy management configuration } \\
\text { with the help of evaluation of maturity level. }\end{array}$ & $\begin{array}{l}\text { The model considers inclusion of energy manger, precisely } \\
\text { a dedicated energy management team. In addition, top } \\
\text { management support is integrated with the considered } \\
\text { attributes in the model. }\end{array}$ & [46] \\
\hline & $\begin{array}{l}\text { Incorporation of qualitative metrics; assessment model implies } \\
\text { on PDCA cycle; inclusion of SWOT analysis tool, incorporation } \\
\text { of global energy management team and external peers. }\end{array}$ & $\begin{array}{l}\text { Incorporates their application specific purposes which are } \\
\text { descriptive, prescriptive, and comparative. Features with } \\
\text { manifold energy management practices along with energy } \\
\text { manager. }\end{array}$ & [66] \\
\hline
\end{tabular}


Table 5. Conts.

\begin{tabular}{|c|c|c|c|}
\hline Category & Model Narration & Remark & Reference \\
\hline & $\begin{array}{l}\text { Consists of three features: (1) energy efficiency features (2) } \\
\text { energy efficiency maturity levels; ( } 3 \text { implementation method } \\
\text { which is accustomed from ZED scheme especially for SMEs. } \\
\text { Seven dimensions: management obligation, arrangement and } \\
\text { procedure, compliance of regulation and fiscal enticements, } \\
\text { archiving system, product and procedure innovation, in-house } \\
\text { communication, and ethos. Consists of nineteen characteristics. }\end{array}$ & $\begin{array}{l}\text { Total number of nineteen energy efficiency characteristics } \\
\text { are integrated in the model. In addition, management } \\
\text { commitment is segregated into two sections in the form of } \\
\text { strategic priority and energy policy. }\end{array}$ & {$[67]$} \\
\hline \multirow[b]{3}{*}{$\begin{array}{l}\text { Energy } \\
\text { Management } \\
\text { Matrixes }\end{array}$} & $\begin{array}{l}\text { Five levels of energy management matrixes to address six } \\
\text { institutional aspects that are policy, organization, motivation, } \\
\text { information scheme, marketing, and financing. }\end{array}$ & $\begin{array}{l}\text { Top management support is fully integrated into the } \\
\text { framework under policy section. Energy managerial role } \\
\text { included in organizational structure. }\end{array}$ & [68] \\
\hline & $\begin{array}{l}\text { Five levels of energy management matrixes to assess six } \\
\text { institutional issues that are energy management scheme; } \\
\text { organization; staff inspiration; tracking, supervision and } \\
\text { reporting systems; staff consciousness/training and promotion, } \\
\text { and financing. }\end{array}$ & $\begin{array}{l}\text { Energy manager feature is integrated with a proposition of } \\
\text { organizational structure. Moreover, energy management is } \\
\text { considered comprehensively in this framework. }\end{array}$ & [55] \\
\hline & $\begin{array}{l}\text { Five levels of energy management matrixes to assess six } \\
\text { institutional issues which are policy or specific guidelines, } \\
\text { coordinating, training, evaluation of performance, } \\
\text { communication, and financing. Valuation model exploring the } \\
\text { subsequent aspects reflected as energy management practice: } \\
\text { policy and legislation, energy blueprint, organizational } \\
\text { formation; regulation; acquisition strategy, financing scheme, } \\
\text { observation, and analysis of energy consumption, setting of goal; } \\
\text { identification of possible options; staff involvement and training; } \\
\text { operational process; communications. }\end{array}$ & $\begin{array}{l}\text { The Carbon Trust guidelines comprised of five aspects. } \\
\text { Inclusion of dedicated energy manager is not integrated to } \\
\text { this model. However, the model incorporates senior } \\
\text { management commitment to enhance energy efficiency } \\
\text { related initiatives. }\end{array}$ & {$[56]$} \\
\hline
\end{tabular}


Table 5. Conts.

\begin{tabular}{|c|c|c|c|}
\hline Category & Model Narration & Remark & Reference \\
\hline & $\begin{array}{l}\text { Model exploring the succeeding features considered as energy } \\
\text { management practice: energy director appointment, } \\
\text { incorporation of energy team, apply of energy policy; collection } \\
\text { of information and management, establishment of yardstick or } \\
\text { threshold, analysis, assessing from technical perspective and } \\
\text { energy audits; exploring and setting the scope, improvement } \\
\text { option estimation, goal setting; define technical procedures and } \\
\text { targets, roles and resources determination; formation of a } \\
\text { communication plan, awareness raising, capacity building, } \\
\text { inspire, trail and monitor; measurement of result, recapitulation } \\
\text { of action plan; maintain internal recognition, and receiving } \\
\text { external appreciation. }\end{array}$ & $\begin{array}{l}\text { The ENERGY STAR guideline clearly emphasizes on } \\
\text { appointment of energy director with dedicated energy team. } \\
\text { In addition, the model looks to establish baselines for } \\
\text { measuring energy performance. }\end{array}$ & [57] \\
\hline \multirow{2}{*}{$\begin{array}{l}\text { EEMs } \\
\text { characterization } \\
\text { framework }\end{array}$} & $\begin{array}{l}\text { Three main characteristics are considered. Each characteristic are } \\
\text { divided into sub-divisions. The first character "Relative } \\
\text { advantage" is attributed by internal rate of return, introductory } \\
\text { expenses, reimbursement time, and benefits of non-energy. } \\
\text { "Technical context" the second character is attributed by } \\
\text { modification type, impact opportunity, gap among core } \\
\text { processes, and Lifetime. The last character "Information context" } \\
\text { is attributed by transaction expenses, planning and execution } \\
\text { knowledge, Dissemination progress, and field wise } \\
\text { applicableness. }\end{array}$ & $\begin{array}{l}\text { One of the salient features of this framework is inclusion of } \\
\text { non-energy benefits. Energy manager is not integrated into } \\
\text { the framework. }\end{array}$ & {$[58]$} \\
\hline & $\begin{array}{l}\text { Economic characterization consists of payback time, application } \\
\text { costs. Energy is attributed with resource stream and energy } \\
\text { saving. Environmental characterization is attributed by waste } \\
\text { minimization and emission contraction. Production is attributed } \\
\text { by productivity, working environment, and operation and } \\
\text { maintenance. Implementation related attributes are energy } \\
\text { saving strategy, types of action, implementation easiness, success } \\
\text { probability, community engagement in corporate level, distance } \\
\text { among key processes, and audit regularity. Interaction-related } \\
\text { characterization is attributed by indirect effects. }\end{array}$ & $\begin{array}{l}\text { Corporate involvement is one of the notable attributes and } \\
\text { considered as significant for industrial decision-makers. } \\
\text { The need for analyzing energy efficiency measures as per } \\
\text { different perspectives is highlighted; precisely having the } \\
\text { aspects in grouped for providing more inclusive view on } \\
\text { the pertinent outlooks distinguishing the energy efficiency } \\
\text { measures. }\end{array}$ & [59] \\
\hline
\end{tabular}




\section{Discussion}

The energy management frameworks were mainly researched to adopt energy management practices at the technical levels in the industries. However, the reviewed papers emphasized the energy management system, ISO 50001, and PDCA cycle, while some studies suggested holistic approaches towards industrial energy efficiency.

The framework proposed by Christoffersen et al. was stood out on the Danish industries and emphasized on multiple factors, mostly energy policy, goals and capstone projects aimed at energy savings. Regulation, external relations, company characteristics, and organizational internal condition are the main out-layers of the model to frame the energy management. However, the company size and energy intensity are two factors that can be considered to categorize the industries to apply or analyze the model [44]. The main features proposed by Christofferen et al. align with ISO 50001: 2011 standard though this model has been replaced by ISO 50001: 2018 [58]. The earlier model encompassed energy management system implementation based on PDCA cycle and enlisted few prerequisites that include mainly management liability, policy, energy audit, energy performance indexing, energy management blueprint, documentation, and so forth. One of the major changes in the recent model is the PDCA cycle modification. "Checking" was the center in the earlier version, whilst "Leadership" became the focus of all cycle components. Figure 3 represents the revised PDCA cycle of ISO 50001:2018. In the minimum requirement segment, the model proposed by Ates et al. comprehended conventional streams towards energy management. One of the significant features is the inclusion of energy manager, whilst ISO 40001 (environmental permit) also act as an enabling feature along with ISO 50001 [40].

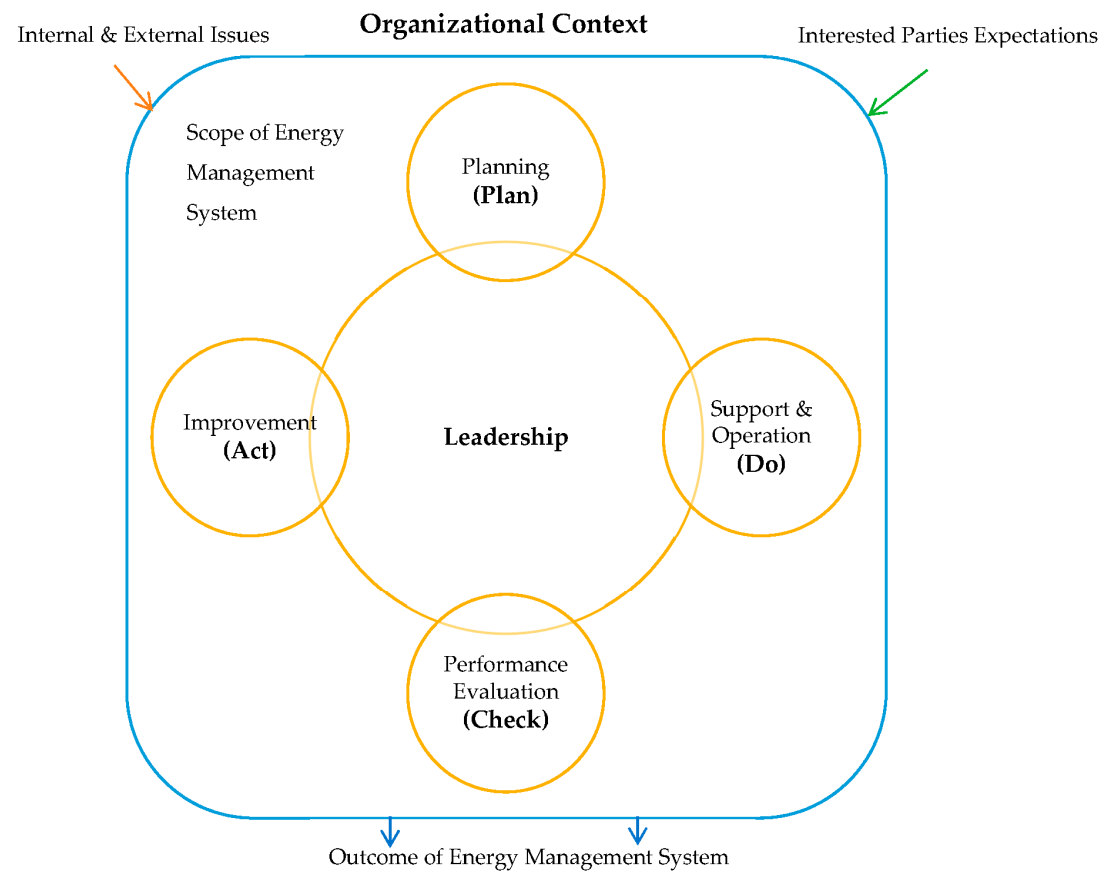

Figure 3. The "Plan-Do-Check-Act" cycle adopted in ISO 50001: 2018 (Source: [45]).

Looking at the minimum requirement focused model, it is observed that all the energy management initiatives are not integrated into the frameworks. Christoffersen et al. [44] considered energy management as a comprehensive management system. However, the model does not integrate the energy manager concept. Furthermore, there is no clear guideline about top or mid-level management support to achieve energy savings. Though, the involvement of employee to energy-saving related works are suggested. Nonetheless, The ISO 50001 model is a significant protocol [69] along with the proposition by Ates and Durakbasa [40], manifold aspects are still to be explored regards of operational activities in the industrial energy management domain. For instance, the principles of sustainability and integral management need to be presented at the protocol. In addition, there is very 
little contribution on the risk management and opportunities of energy efficiency from an integral and strategic point of view, including the planning and control of product lines, process design, projects, and business approaches [69]. Notably, the fruitful operation of the energy management system requires the integrated deployment of planned, tactical, and operational levels that align the business culture with sustainable attainment. In this context, the vision that the organization plans to form should be linked to energy efficiency strategy with organization's survival plan in the market. Additionally, it is necessary to make explicit reference to newly adapted technical features through peer to peer energy management platform for optimizing the integration of energy management system component with the variable energy demand [70,71]. Moreover, an integrated perspective to control of operational features of each process are required to explore linked to energy efficiency [69].

In the energy management maturity model segment, the model proposed by Ngai et al. based on capability maturity model integration (CMMI), an extension of capability maturity model incorporated five levels according to the behavioral exhibition of the industries [54]. The levels are determined by performance area of key processes [72]. The achievement goals of key process areas must be specified for individual level for further actions. Notably, the propositions of CMM framework has been applied at multiple process enhancement programs in order to achieve the desired quality in the production system [73]. One limitation of this model is inadequate implementation time, having only one factory for consideration. However, the authors have affirmed the acceptability of the model because of prior implementation of management practices. On the contrary, Antunes et al. emphasized the PDCA cycle to design the energy management framework [64]. Additionally, the authors implied the model with ISO 50001 and incorporated energy management practices also. Notable to mention that Finnerty et al. also designed the framework based on the PDCA cycle, keeping on focus on energy management practices [66].

The model proposed by Introna et al. is comprised of five dimensions and enables the feature of self-evaluation for the industries towards energy management practices. The dimensions are characterized by identifying the necessary elements in energy management consumption segment of the industries [8]. On the contrary, Jovanović et al. focused on ISO 50001 processes as well as PDCA phases, keeping the knowledge base in the model EMMM50001 [53]. The EMMM50001 establishes the relation to EUMMM maturity levels, maintaining ISO 50001 specifications and PDCA phases. Notably to mention that EMMM50001 links the CMMI criteria, also maintaining the ISO 50001.

It can be observed that the majority of the maturity models emphasized on similar type of characteristics and areas to evaluate the energy management in an organization by a systematic set of commendations. However, the narrated models demand more time and resources to perform as per their characterization. In addition, looking at the scientific literature, all of the frameworks studied to see the requirements for providing a continuous development path following the PDCA approach and ISO 50001. Notably, few of the maturity models incorporate the implication of dedicated energy manager and top management support. In contrast, Antunes et al. [64] affirm on top management support whilst not integrating the energy manager in the framework. The framework by Introna et al. [8] also did not complied with the energy manager. Nonetheless, Jovanović and Filipović [53] and Finnerty et al. [66] considered top management support along with the energy manager in their framework.

Gordic' et al. applied the energy management matrixes model in the Serbian car manufacturer industries and critically analyzed the existing energy management system with the model [55]. Notably to mention that the energy management matrixes models proposed by Gordic' et al., Carbon Trust and Energy Star encompass all key areas to assess the energy management practices in the model, with having few modifications at the individual version.

On the contrary, Fleiter et al. [58] and Trianni et al. [52] emphasized on a characterization based model where both of the models are incorporated with specific attributes. The characterization scheme has some implications on policy design and assessment. However, formalization of the groups with categorized attributes enables the option towards relevant aspects identifying the energy efficiency measures. In addition, Trianni et al. contend a comprehensive scenario on EEMs focusing on the relevant aspects of industrial energy management [52]. One of the critical factors, "corporate involvement" 
for industrial decision-makers is also implied, hence allowing additional feature and an increase in the applicability of the model. In another proposed framework, Trianni et al. incorporated energy management practice-based approach. However, the authors acknowledge more compatible space for the SMEs within the model, as SMEs are sought to be entitled to more attention, considering their cumulative energy consumption percentile [74]. In a recent study, Tina et al. persuade the significance of SMEs and the policy implications in the peripheral of the industrial energy sector [74]. Referring to the SMEs, Prashar [67] proposes an energy efficiency maturity assessment framework that emphasizes SMEs. Notably, the author argues that the common energy efficiency framework approach does not facilitate fully to the SMEs; hence, a customized maturity framework is significant. The author considered steel re-rolling mill sector of India as the contextual sphere for the proposed framework.

Few of the studies on characterization the energy efficiency measure focuses on financial features. Notably to mention that these models do not frame the energy efficiency measures comprehensively, rather offer some framework without characterizing the energy efficiency measures in-depth. In one of the studies by Pye and McKane, they state that quantification of the accumulated benefits of energy efficiency scheme supports the enterprises perceive the monetary opportunities of EEMs financing [5]. The energy savings features act not as the singular primary driver for the industrial decision process; hence, the authors persuade that energy savings be viewed as a factor of the holistic approach towards energy efficiency programs. Skumatz studied the methods to find out the attributes of EEMs and established the scheme to measure both of the positive and negative secondary benefits stemming from industrial energy efficiency schemes $[75,76]$. On the contrary, Mills and Rosenfeld provided a framework to understand multiple benefits of energy efficiency initiatives and grouped the attributes into the better interior environment, noise lessening, savings of labor and time, improved supervision of procedure, convenience, water savings and waste reduction, and benefits due to downsizing of equipment [77].

The majority of studies on energy efficiency measures, benefits, and initial characterization frameworks propose few interesting reflections. However, a lack of consistency on the attributes grouping within existing categories from the methodological perspective is observed. It is found that the same attributes are grouped in different categories by different researchers. Moreover, the attributes are categorized and then aggregated again within other segments by different researcher. For instance, "reduced noise" and "improved indoor environment" are framed in two different categories in [77], whereas "reduced noise level" as categorized in "working environment" segment. On the other note, the decision-making process is a grey area keeping mind about the stakeholders. Nonetheless, the earlier characterization framework did not incorporate the energy efficiency measure implications in a comprehensive way. To be precise, the inclusion of non-energy benefits is not incorporated into the characterization framework. Notably, the inclusion of non-energy features in the modeling factors would double the cost-effective potential for energy-efficiency enhancement, likened to an analysis eliminating those benefit [60]. However, few attributes (e.g., improved air quality, better worker safety, reduction of noise level, and improved working situation) are there in the characterization framework, which are difficult to quantify [76]. Therefore, speculation is required to articulate the benefits into a comparable cost figure, and hence the assessment turns out to be rather subjective [60].

The study by Ngai et al. [54] features energy management with particular process areas in the manufacturing industries. In this study, few guidelines are offered to conduct analysis for organizational maturity improvement in terms of energy along with the management of utility resources. However, the integration of energy management into production process has not been complied comprehensively. This is a significant avenue that needs be to address with utmost attention in future studies considering the technical implications offered by Industry 4.0. Notable to mention here, is that increasing the efficiency at the production processes is one of the salient features of Industry 4.0 [78]. The deployment of smart machinery offers diverse benefits which primarily includes manufacturing productivity and waste reduction [79]. Therefore, it is worth observing the energy management characteristics linked with production process through the lens of Industry 4.0. 
Nonetheless, energy management towards industrial energy efficiency has been widely discussed in academia, and several barriers are still persistent in the energy management domain. The identification of barriers is important because it hampers or slows down the adoption of energy efficiency measures [80]. Several studies have addressed the barriers which cover energy-intensive industries to SMEs and include regional, national, and transnational perspectives [15,26,27,81-84]. However, most comprehensive studies focusing on energy management have been discussed without really looking at the integration of energy management into production and operation management. An imperative avenue, therefore, lies to be further explored in future within this research domain.

\section{Concluding Remarks and Future Research Avenues}

The paper attributes a review of research works on the energy management model for energy management practices in the industries. Multiple models have been compiled and structured, maintaining the narrations. Moreover, the energy management frameworks were synthesized emanate from the findings in order to facilitate energy management in the industries by offering necessary benchmarks to the industrial experts. The review findings show that the narrated models can support an organization to assess energy management and incorporate insightful contribution to energy efficiency initiatives. Nonetheless, some of the studies did not comply with a full methodological description and exhibited shorter model validation. In addition, a gap exists between the theoretical concept and practical implementation of energy management and its practices. Precisely, majority approaches remain unsuccessful in replicating and scope of actions distinct in energy management due to the certain barriers $[27,66,85]$.

Moreover, most of the models have looked the energy management as a single unit function, whilst it is a combination of multi-dimensional approaches with the involvement of several functional units in the industries. Let us not forget about the multi-dimensional operational activities in the industries which are conjugal part with energy management. Notably, multi-dimensional approaches are critical to support the process and operational oriented program [86]. Therefore, a comprehensive operational approach should be considered by integrating all the relevant energy flows. It infers to all forms of energy, including externally supplied energy sources as well as internal energy flows. Interestingly, relating the energy management into the operational framework integrates the resource efficiency also at the manufacturing level. The raw or auxiliary material consumption might be of interest, considering the direct and indirect impact on energy and resource efficiency in the manufacturing process. Moreover, keeping mind about the non-static nature of energy consumption, the dynamic consumption feature might unveil manifold resource optimization aspects [87].

Unfortunately, the integration of energy management into operational activities have been little explored. It becomes even more imperative while we look to adopt Industry 4.0 keeping in mind about the manifold complex technical features consist of Internet of Things (IoT), big data, cloud computing, and so on in the industrial plants. Many scholars predict that the exponential progress in the promises of manifold technical features offered by Industry 4.0 might affect the production activities in the industries inclusively. In addition, there are high chances of modification in the traditional industrial actions that cover the processing of elements and material, grinding, and assemble/ dismantle. This is emphasized in Industry 4.0 concept and its implementation, where we pursue to pool the common features with the enormous potential of digital technology [88]. However, it is understood as a necessary incremental approach aimed at further optimizing the energy system without seeking to disrupt it in principle. In the energy efficiency domain, the energy management and its practices have already influenced the production scenario in a broader aspect, and this inclination should remain as long as we allow the nexus between Industry 4.0 and energy efficiency. On the other hand, energy productivity investments in present as well as the recent technologies must be conveyed through the implementation of energy management and its practices [89]. Energy management practices and energy services are acknowledged as fundamental solutions; the diminutive effort is being paid in characterizing them [24]. Notably, assessment models for supporting the industrial decision-makers 
emphasizing detailed activities for better energy management is deficient. Therefore, it is imperative to consider the energy management in multiple aspects keeping mind about the complex nature of industrial energy system [31].

Interestingly, energy management has implications on asset maintenance, e.g., on maintenance procedures. As energy management includes the control of energy-consuming devices to optimize energy consumption, manual toggling on and off devices depending on requirement is a rudimentary custom of energy management. The initiation of mechanical and electrical equipment (e.g., timers for programmed toggling, bimetallic strip thermostat, pneumatic and electrical transmission system, and so on) provided means for early energy management schemes in the form of automatic temperature control. Nowadays, the inclusion of direct digital control in energy management has retrofit benefits that allow device monitoring linked to maintenance procedure, thanks to energy management and its practices. The comprehensive data recommend that while energy management does improve the accuracy and response of a system in the industries, the energy management routines facilitate partially asset maintenance [90]. It infers to monitoring or log building equipment performance while consuming the energy resulting increasing magnitude of all benefits covering maintenance and cost avoidance benefit. Unfortunately, much of the energy management studies have bypassed this retrofit fact while focusing on the energy management framework. So far, the integration of energy management with asset management has not been widely explored, and several questions remain unanswered at present. Therefore, more research needs to be undertaken to fit the asset maintenance into energy management framework in a comprehensive way.

In addition, the narrated models have little explored the sustainability feature integrated with energy efficiency, pointing to the optimization of resource utilization [91]. We must consider the paradigm that allows industrial energy management effective for the companies. In this context, it would be certainly interesting to visualize the energy management through Industry 4.0 technologies and solutions, may contribute to improved sustainability performances of the companies. If Industry 4.0 is expected to unveil enormous directions not only to energy management but also the sustainability field, the challenge definitely lies on the integrational aspects with energy-industry-sustainability nexus. Therefore, the future research avenues should reflect the energy management framework complying the diverse directions and encompassing the operational management, Industry 4.0 along with sustainability features.

Author Contributions: Conceptualization, A.S.M.M.H. and A.T.; methodology, A.S.M.M.H. and A.T.; formal analysis, A.S.M.M.H. and A.T.; investigation, A.S.M.M.H. and A.T.; writing-original draft preparation, A.S.M.M.H. and A.T.; writing-review and editing, A.S.M.M.H. and A.T.; visualization, A.T.; supervision, A.T. All authors have read and agreed to the published version of the manuscript.

Funding: This research received no external funding.

Conflicts of Interest: The authors declare no conflict of interest.

\section{Nomenclature}

$\begin{array}{ll}\text { EMP } & \text { Energy Management Practice } \\ \text { EEM } & \text { Energy Efficiency Measure } \\ \text { ESM } & \text { Energy Saving Measure } \\ \text { SME } & \text { Small- and Medium-sized Enterprise } \\ \text { GHG } & \text { Greenhouse Gases } \\ \text { CMM } & \text { Capability Maturity Model } \\ \text { PDCA } & \text { Plan-Do-Check-Act } \\ \text { CMMI } & \text { Capability Maturity Model Integration } \\ \text { EMMM50001 } & \text { ISO 50001-based Energy Management Maturity Model } \\ \text { ISO } & \text { International Organization for Standardization } \\ \text { EnMS } & \text { Energy Management System } \\ \text { EUMMM } & \text { Energy and Utility Management Maturity Model }\end{array}$




\section{References}

1. Faheem, M.; Gungor, V.C. Energy efficient and QoS-aware routing protocol for wireless sensor network-based smart grid applications in the context of industry 4.0. Appl. Soft Comput. J. 2018, 68, 910-922. [CrossRef]

2. Tesch da Silva, F.S.; da Costa, C.A.; Paredes Crovato, C.D.; da Rosa Righi, R. Looking at energy through the lens of Industry 4.0: A systematic literature review of concerns and challenges. Comput. Ind. Eng. 2020, 143, 106426. [CrossRef]

3. König, W. Energy efficiency in industrial organizations-A cultural-institutional framework of decision making. Energy Res. Soc. Sci. 2020, 60, 101314. [CrossRef]

4. Cagno, E.; Neri, A.; Trianni, A. Broadening to sustainability the perspective of industrial decision-makers on the energy efficiency measures adoption: Some empirical evidence. Energy Effic. 2018, 11, 1193-1210. [CrossRef]

5. Pye, M.; McKane, A. Making a stronger case for industrial energy efficiency by quantifying non-energy benefits. Resour. Conserv. Recycl. 2000, 28, 171-183. [CrossRef]

6. Bunse, K.; Vodicka, M.; Schönsleben, P.; Brülhart, M.; Ernst, F.O. Integrating energy efficiency performance in production management-Gap analysis between industrial needs and scientific literature. J. Clean. Prod. 2011, 19, 667-679. [CrossRef]

7. Sola, A.V.H.; Mota, C.M.M. Influencing factors on energy management in industries. J. Clean. Prod. 2020, 248, 119263. [CrossRef]

8. Introna, V.; Cesarotti, V.; Benedetti, M.; Biagiotti, S.; Rotunno, R. Energy Management Maturity Model: An organizational tool to foster the continuous reduction of energy consumption in companies. J. Clean. Prod. 2014, 83, 108-117. [CrossRef]

9. Hirst, E.; Brown, M. Closing the efficiency gap: Barriers to the efficient use of energy. Resour. Conserv. Recycl. 1990, 3, 267-281. [CrossRef]

10. Cagno, E.; Worrell, E.; Trianni, A.; Pugliese, G. A novel approach for barriers to industrial energy efficiency. Renew. Sustain. Energy Rev. 2013, 19, 290-308. [CrossRef]

11. Anderson, S.T.; Newell, R.G. Information programs for technology adoption: The case of energy-efficiency audits. Resour. Energy Econ. 2004, 26, 27-50.

12. Cagno, E.; Trianni, A. Analysis of the Most Effective Energy Efficiency Opportunities in Manufacturing Primary Metals, Plastics, and Textiles Small- and Medium-Sized Enterprises. J. Energy Resour. Technol. 2012, 134. [CrossRef]

13. Jaffe, A.B.; Stavins, R.N. The energy-efficiency gap What does it mean? Energy Policy 1994, 22, 804-810.

14. Johansson, M.T. Improved energy efficiency within the Swedish steel industry-The importance of energy management and networking. Energy Effic. 2015, 8, 713-744.

15. Brunke, J.C.; Johansson, M.; Thollander, P. Empirical investigation of barriers and drivers to the adoption of energy conservation measures, energy management practices and energy services in the Swedish iron and steel industry. J. Clean. Prod. 2014, 84, 509-525. [CrossRef]

16. Hasan, A.S.M.M.; Rokonuzzaman, M.; Tuhin, R.A.; Salimullah, S.M.; Ullah, M.; Sakib, T.H.; Thollander, P. Drivers and Barriers to Industrial Energy Efficiency in Textile Industries of Bangladesh. Energies 2019, 12, 1775. [CrossRef]

17. Soepardi, A.; Thollander, P. Analysis of Relationships among Organizational Barriers to Energy Efficiency Improvement: A Case Study in Indonesia's Steel Industry. Sustainability 2018, 10, 216.

18. Trianni, A.; Cagno, E.; Thollander, P.; Backlund, S. Barriers to industrial energy efficiency in foundries: A European comparison. J. Clean. Prod. 2013, 40, 161-176.

19. Trianni, A.; Cagno, E.; Farné, S. Barriers, drivers and decision-making process for industrial energy efficiency: A broad study among manufacturing small and medium-sized enterprises. Appl. Energy 2016, 162, 1537-1551.

20. Cagno, E.; Trianni, A.; Spallina, G.; Marchesani, F. Erratum to: Drivers for energy efficiency and their effect on barriers: Empirical evidence from Italian manufacturing enterprises. Energy Effici. 2017, 10, 855-869, 10.1007/s12053-016-9488-x.

21. Trianni, A.; Cagno, E.; Marchesani, F.; Spallina, G. Classification of drivers for industrial energy efficiency and their effect on the barriers affecting the investment decision-making process. Energy Effic. 2017, 10, 199-215. [CrossRef]

22. Apeaning, R.W.; Thollander, P. Barriers to and driving forces for industrial energy efficiency improvements in African industries-A case study of Ghana's largest industrial area. J. Clean. Prod. 2013, 53, 204-213. [CrossRef] 
23. Gangolells, M.; Casals, M.; Forcada, N.; Macarulla, M.; Giretti, A. Environmental impacts related to the commissioning and usage phase of an intelligent energy management system. Appl. Energy 2015, 138, $216-223$.

24. Sa, A.; Paramonova, S.; Thollander, P.; Cagno, E. Classification of Industrial Energy Management Practices: A Case Study of a Swedish Foundry. Energy Procedia 2015, 75, 2581-2588.

25. Trianni, A.; Cagno, E.; Bertolotti, M.; Thollander, P.; Andersson, E. Energy management: A practice-based assessment model. Appl. Energy 2019, 235, 1614-1636.

26. Hasan, A.S.M.M.; Hoq, M.T.; Thollander, P. Energy management practices in Bangladesh's iron and steel industries. Energy Strateg. Rev. 2018, 22, 230-236.

27. Thollander, P.; Ottosson, M. Energy management practices in Swedish energy-intensive industries. J. Clean. Prod. 2010, 18, 1125-1133.

28. Hasan, A.S.M.M.; Hossain, R.; Tuhin, R.A.; Sakib, T.H.; Thollander, P. Empirical Investigation of Barriers and Driving Forces for Efficient Energy Management Practices in Non-Energy-Intensive Manufacturing Industries of Bangladesh. Sustainability 2019, 11, 2671.

29. Backlund, S.; Thollander, P. Thollander the energy-service gap. What does it mean? In Proceedings of the ECEEE 2011 Summer Study, Hyères, France, 6-11 June 2011; pp. 649-656.

30. Good, N.; Martínez Ceseña, E.A.; Zhang, L.; Mancarella, P. Techno-economic and business case assessment of low carbon technologies in distributed multi-energy systems. Appl. Energy 2016, 167, 158-172.

31. Kannan, R.; Boie, W. Energy management practices in SME-Case study of a bakery in Germany. Energy Convers. Manag. 2003, 44, 945-959. [CrossRef]

32. Schulze, M.; Nehler, H.; Ottosson, M.; Thollander, P. Energy management in industry-A systematic review of previous findings and an integrative conceptual framework. J. Clean. Prod. 2016, 112, 3692-3708. [CrossRef]

33. Denyer, D.; Tranfield, D. Producing a Systematic Review. In The SAGE Handbook of Organizational Research Methods; Sage Publications Ltd.: Thousand Oaks, CA, USA, 2009; pp. 671-689. ISBN 9781412931182.

34. Higgins, J.P.; Green, S. Cochrane Handbook for Systematic Reviews of Interventions: Cochrane Book Series; John Wiley and Sons: Hoboken, NJ, USA, 2008; ISBN 9780470699515.

35. Martín-Martín, A.; Orduna-Malea, E.; Thelwall, M.; Delgado López-Cózar, E. Google Scholar, Web of Science, and Scopus: A systematic comparison of citations in 252 subject categories. J. Informetr. 2018, 12, 1160-1177. [CrossRef]

36. Podsakoff, P.M.; MacKenzie, S.B.; Bachrach, D.G.; Podsakoff, N.P. The influence of management journals in the 1980s and 1990s. Strateg. Manag. J. 2005, 26, 473-488. [CrossRef]

37. Kahlenborn, W.; Kabisch, S.; Klein, J.; Ina Richter, S.S. Energy Management-Systems in Practice: A Guide for Companies and Organisations; Federal Ministry for the Environment, Nature Conservation and Nuclear Safety: Bonn, Germany, 2010; p. 12.

38. Capehart, B.L.; Turner, W.C.; Kennedy, W.J. Guide to Energy Management, 5th ed.; The Fairmont Press: Lilburn, GA, USA, 2006; ISBN 0881734772.

39. O'Callaghan, P.W.; Probert, S.D. Energy management. Appl. Energy 1977, 3, 127-138. [CrossRef]

40. Ates, S.A.; Durakbasa, N.M. Evaluation of corporate energy management practices of energy intensive industries in Turkey. Energy 2012, 45, 81-91. [CrossRef]

41. Abdelaziz, E.A.; Saidur, R.; Mekhilef, S. A review on energy saving strategies in industrial sector. Renew. Sustain. Energy Rev. 2011, 15, 150-168. [CrossRef]

42. Rasmussen, J. The additional benefits of energy efficiency investments-A systematic literature review and a framework for categorisation. Energy Effic. 2017, 10, 1401-1418. [CrossRef]

43. Mckane, A.; Williams, R.; Perry, W. Setting the Standard for Industrial Energy Efficiency Permalink. In Proceedings of the Conference on Energy Efficiency in Motor Driven Systems, Beijing, China, 10-13 June 2007.

44. Christoffersen, L.B.; Larsen, A.; Togeby, M. Empirical analysis of energy management in Danish industry. J. Clean. Prod. 2006, 14, 516-526. [CrossRef]

45. ISO 50001:2018(en), Energy Management Systems—Requirements with Guidance for Use. Available online: https://www.iso.org/obp/ui/\#iso:std:iso:50001:ed-2:v1:en (accessed on 18 October 2020).

46. Sa, A.; Thollander, P.; Cagno, E. Assessing the driving factors for energy management program adoption. Renew. Sustain. Energy Rev. 2017, 74, 538-547. [CrossRef]

47. Weber, C.V.; Curtis, B.; Chrissis, M.B. Capability Maturity Model, Version 1.1. IEEE Softw. 1993, 10, 18-27.

48. Becker, J.; Knackstedt, R.; Pöppelbuß, J. Developing Maturity Models for IT Management. Bus. Inf. Syst. Eng. 2009, 1, 213-222. [CrossRef] 
49. Scott, J.E. Mobility, business process management, software sourcing, and maturity model trends: Propositions for the IS organization of the future. Inf. Syst. Manag. 2007, 24, 139-145. [CrossRef]

50. Lahrmann, G.; Marx, F.; Mettler, T.; Winter, R.; Wortmann, F. Inductive Design of Maturity Models: Applying the Rasch Algorithm for Design Science Research; Springer: Berlin/Heidelberg, Germany, 2011; Volume 6629, ISBN 9783642206320.

51. CMMI Product Team. CMMI for Development, Version 1.3; Software Engineering Institute, Carnegie Mellon University: Pittsburgh, PA, USA, 2010.

52. Proença, D.; Borbinha, J. Maturity Models for Information Systems-A State of the Art. In Proceedings of the Procedia Computer Science; Elsevier: Amsterdam, The Netherlands, 2016; Volume 100, pp. 1042-1049.

53. Jovanović, B.; Filipović, J. ISO 50001 standard-based energy management maturity model-Proposal and validation in industry. J. Clean. Prod. 2016, 112, 2744-2755. [CrossRef]

54. Ngai, E.W.T.; Chau, D.C.K.; Poon, J.K.L.; To, C.K.M. Energy and utility management maturity model for sustainable manufacturing process. Int. J. Prod. Econ. 2013, 146, 453-464. [CrossRef]

55. Gordić, D.; Babić, M.; Jovičić, N.; Šušteršič, V.; Končalović, D.; Jelić, D. Development of energy management system-Case study of Serbian car manufacturer. Energy Convers. Manag. 2010, 51, 2783-2790. [CrossRef]

56. Carbon Trust. Energy Management-A Comprehensive Guide to Controlling Energy Use; Carbon Trust: London, UK, 2011.

57. ENERGY STAR. Guidelines for Energy Management; ENERGY STAR: Oakland, CA, USA, 2012.

58. Fleiter, T.; Hirzel, S.; Worrell, E. The characteristics of energy-efficiency measures-A neglected dimension. Energy Policy 2012, 51, 502-513. [CrossRef]

59. Trianni, A.; Cagno, E.; De Donatis, A. A framework to characterize energy efficiency measures. Appl. Energy 2014, 118, 207-220. [CrossRef]

60. Worrell, E.; Laitner, J.A.; Ruth, M.; Finman, H. Productivity benefits of industrial energy efficiency measures. Energy 2003, 28, 1081-1098. [CrossRef]

61. Lung, R.B.; McKane, A.; Leach, R.; Marsh, D. Ancillary Savings and Production Benefits in the Evaluation of Industrial Energy Efficiency Measures. In Proceedings of the 2005 American Council for an Energy-Efficient Economy Summer Study on Energy Efficiency in Industry; ACEEE: Washington, DC, USA, 2005; pp. 103-114.

62. Sorrell, S. The economics of energy service contracts. Energy Policy 2007, 35, 507-521. [CrossRef]

63. Benedetti, M.; Cesarotti, V.; Holgado, M.; Introna, V.; Macchi, M. A proposal for energy services' classification including a product service systems perspective. In Proceedings of the Procedia CIRP; Elsevier: Amsterdam, The Netherlands, 2015; Volume 30, pp. 251-256.

64. Antunes, P.; Carreira, P.; Mira da Silva, M. Towards an energy management maturity model. Energy Policy 2014, 73, 803-814. [CrossRef]

65. O'Sullivan, J. Energy Management Maturity Model (EM3)—A Strategy to Maximize the Potential for Energy Savings through EnMS. 2012.

66. Finnerty, N.; Sterling, R.; Coakley, D.; Keane, M.M. An energy management maturity model for multi-site industrial organisations with a global presence. J. Clean. Prod. 2017, 167, 1232-1250. [CrossRef]

67. Prashar, A. Energy efficiency maturity (EEM) assessment framework for energy-intensive SMEs: Proposal and evaluation. J. Clean. Prod. 2017, 166, 1187-1201. [CrossRef]

68. Ashford, C.J. Energy Efficiency: A Managed Resource. Facilities 1993, 11, 24-27. [CrossRef]

69. ISO 50001:2011(en), Energy Management Systems-Requirements with Guidance for Use. Available online: https://www.iso.org/obp/ui/\#iso:std:iso:50001:ed-1:v1:en (accessed on 11 April 2020).

70. Mao, M.; Jin, P.; Hatziargyriou, N.D.; Chang, L. Multiagent-based hybrid energy management system for microgrids. IEEE Trans. Sustain. Energy 2014, 5, 938-946. [CrossRef]

71. Blaauwbroek, N.; Nguyen, P.H.; Konsman, M.J.; Shi, H.; Kamphuis, R.I.G.; Kling, W.L. Decentralized Resource Allocation and Load Scheduling for Multicommodity Smart Energy Systems. IEEE Trans. Sustain. Energy 2015, 6, 1506-1514. [CrossRef]

72. Jokela, T.; Siponen, M.; Hirasawa, N.; Earthy, J. A survey of usability capability maturity models: Implications for practice and research. Behav. Inf. Technol. 2006, 25, 263-282. [CrossRef]

73. Krishnan, M.S.; Kriebel, C.H.; Kekre, S.; Mukhopadhyay, T. An Empirical Analysis of Productivity and Quality in Software Products. Manag. Sci. 2000, 46, 745-759. [CrossRef]

74. Fawcett, T.; Hampton, S. Why \& how energy efficiency policy should address SMEs. Energy Policy 2020, 140, 111337. 
75. Skumatz, L.A.; Dickerson, C.A. Extra! Extra! Non-Energy Benefits Swamp Load Impacts For PG\&E Program! In Proceedings of the 1998 ACEEE Summer Study, Panel 8, Pacific Grove, CA, USA, 25-31 August 1998; pp. 301-312.

76. Skumatz, L.A.; Gardner, J. Methods and results for measuring non-energy benefits in the commercial and industrial sectors. In Proceedings of the Proceedings ACEEE Summer Study on Energy Efficiency in Industry, Washington, DC, USA, 2005; pp. 163-176.

77. Mills, E.; Rosenfeld, A. Consumer non-energy benefits as a motivation for making energy-efficiency improvements. Energy 1996, 21, 707-720. [CrossRef]

78. Gilchrist, A. Industrial Internet Use-Cases; Apress: Berkeley, CA, USA, 2016.

79. Tortorella, G.L.; Fettermann, D. Implementation of industry 4.0 and lean production in brazilian manufacturing companies. Int. J. Prod. Res. 2018, 56, 2975-2987. [CrossRef]

80. Fleiter, T.; Worrell, E.; Eichhammer, W. Barriers to energy efficiency in industrial bottom-up energy demand models-A review. Renew. Sustain. Energy Rev. 2011, 15, 3099-3111. [CrossRef]

81. Walsh, C.; Thornley, P. Barriers to improving energy efficiency within the process industries with a focus on low grade heat utilisation. J. Clean. Prod. 2012, 23, 138-146. [CrossRef]

82. De Groot, H.L.F.; Verhoef, E.T.; Nijkamp, P. Energy saving by firms: Decision-making, barriers and policies. Energy Econ. 2001, 23, 717-740. [CrossRef]

83. Harris, J.; Anderson, J.; Shafron, W. Investment in energy efficiency: A survey of Australian firms. Energy Policy 2000, 28, 867-876. [CrossRef]

84. Hossain, S.R.; Ahmed, I.; Azad, F.S.; Monjurul Hasan, A.S.M. Empirical investigation of energy management practices in cement industries of Bangladesh. Energy 2020, 212, 118741. [CrossRef]

85. Palm, J.; Thollander, P. An interdisciplinary perspective on industrial energy efficiency. Appl. Energy 2010, 87, 3255-3261. [CrossRef]

86. Nesticò, A.; Somma, P. Comparative Analysis of Multi-Criteria Methods for the Enhancement of Historical Buildings. Sustainability 2019, 11, 4526. [CrossRef]

87. Thiede, S. Energy Efficiency in Manufacturing Systems; Sustainable Production, Life Cycle Engineering and Management; Springer: Berlin/Heidelberg, Germany, 2012; ISBN 978-3-642-25913-5.

88. André, J.-C. Industry 4.0: Paradoxes and Conflicts; Wiley-ISTE: Hoboken, NJ, USA, 2019; ISBN 978-1-786-30482-7.

89. Backlund, S.; Thollander, P.; Palm, J.; Ottosson, M. Extending the energy efficiency gap. Energy Policy 2012, 51, 392-396. [CrossRef]

90. Stephan, A.; Roosa, W.C.T.; Doty, S. Energy Management Handbook, 9th ed.; Fairmont Press: Lilburn, GA, USA, 2018; ISBN 9781138666979.

91. Ghobakhloo, M. Industry 4.0, digitization, and opportunities for sustainability. J. Clean. Prod. 2020, 252, 119869. [CrossRef]

Publisher's Note: MDPI stays neutral with regard to jurisdictional claims in published maps and institutional affiliations.

(C) 2020 by the authors. Licensee MDPI, Basel, Switzerland. This article is an open access article distributed under the terms and conditions of the Creative Commons Attribution (CC BY) license (http://creativecommons.org/licenses/by/4.0/). 